\title{
Seaweed Farmers' Perceptions of Children's Formal Education Level in Bulu-Bulu Village, Tonra District, Bone Regency
}

\author{
Maddatuang $^{1}$, Suprapta $^{2}$, Wildi Winarti ${ }^{3}$ \\ ${ }^{123}$ JURUSAN GEOGRAFI / FAKULTAS MATEMATIKA DAN ILMU PENGETAHUAN \\ ALAM / UNIVERSITAS NEGERI MAKASSAR
}

Email :

$\underline{\text { maddatuang@ac.id }{ }^{1} \text {, suprapta @ unm.ac.id }{ }^{2} \text {,wildiwinarti909@gmail.com }}$

(Received: Agu/2021; Reviewed: Sept/2021; Accepted: Sept/2021; Published: Okt/2021)

Ini adalah artikel dengan akses terbuka dibawah license CC BY-SA @2021 oleh penulis (https://creativecommons.org/licenses/by-nc/4.0/).

\begin{abstract}
This research is a descriptive study that aims to: 1) Knowing the condition of formal education for the children of seaweed farmers in Bulu-Bulu Village. 2) Know how seaweed farmers' perceptions of the level of formal education of children in Bulu-Bulu Village, Tonra District, Bone Regency. 3) Knowing what factors influence the perceptions of seaweed farmers on the level of formal education of children in Bulu-Bulu Village. The population ini this study was 114 housedhold heads. The sampling technique used the Snowball Sampling technique with a sample size of 30 household heads. Data collection was carried out by means of observation, interviews, and documentation. Data analysis technique using descriptive statistical analysis techniques.The results of this study indicate that the most of the formal education conditions of the children of seaweed farmers in the village of Bulu-Bulu, Tonra subdistrict, are mostly still continuing their education at the primary and secondary levels. Perception of seaweed farmers on the level of formal education of children in Bulu-Bulu Village, Tonra District is quite good (positive). Seaweed farmers' perceptions of the level of formal education of children are influenced by factors such as education level, income level, and workload.
\end{abstract}

Keywords: perception; seaweed farmers; formal education for children

\section{ABSTRAK}

Penelitian ini adalah penelitian deskriptif yang bertujuan untuk: 1) Mengetahi bagaimana kondisi pendidikan formal anak petani rumput laut di Desa Bulu-Bulu. 2) Mengetahui bagaimana persepsi petani rumput laut terhadap tingkat pendidikan formal anak di Desa Bulu-Bulu Kecamatan Tonra Kabupaten Bone. 3) Mengetahui faktor apa yang mempengaruhi persepsi petani rumput laut terhadap tingkat pendidikan formal anak di Desa Bulu-Bulu. Populasi dalam penelitian ini adalah 114 kepala rumah tangga. Teknik pengambilan sampel menggunakan teknik Snowball Sampling dengan jumlah sampel 30 kepala rumah tangga. Pengumpulan data dilakukan dengan cara observasi, wawancara, dan dokumentsi. Teknik 
analisis data mengunakan teknik analisis statistik deskriptif. Hasil penelitian ini menunjukkan bahwa kondisi pendidikan formal anak petani rumput laut di Desa Bulu-Bulu Kecamatan Tonra sebagian besar masih melanjutkan pendidikannya pada tingkat dasar dan tingkat menengah. Persepsi petani rumput laut terhadap tingkat pendidikan formal anak di Desa Bulu-Bulu Kecamatan Tonra tergolong cukup baik (Positif). Persepsi petani rumput laut terhadap tingkat pendidikan formal anak dipengaruhi oleh faktor tingkat pendidikan, tingkat pendapatan, dan curahan kerja.

Kata Kunci: persepsi; petani rumput laut; pendidikan formal anak

\section{PENDAHULUAN}

Indonesia merupakan memiliki kondisi laut yang luas dan kaya sumber daya alam. Rumput laut termasuk salah satu prospek perikanan yang ada di Indonesia dengan potensi lahan budidayanya seluas hampir 5 juta hektar (Burdames \& Ngangi, 2014). Dengan melimpahnya sumber daya alam di Indonesia maka tingkat pendidikan formalnya juga harus lebih maju. Namun tingkat Pendidikan formal di Indonesia jika dibandingkan dengan tingkat pendidikan formal negara lain masih dikatakan rendah (Kurniawan, 2016). Padahal kendala tersebut sudah diminimalisir dengan adanya kebijakan pemerintah yang sangat concern terhadap masyarakat miskin untuk dapat memperoleh pendidikan (Tubu et al., 2021).

Pendidikan merupakan salah satu kebutuhan setiap individu dalam kehidupannya. Salah satu yang menjadi investasi yang lebih baik di masa depan (Ustama, 2009). Selain itu peran penting pendidikan sangat berpengaruh dalam meningkatkan kualitas sumberdaya manusia (Yusuf, 2014). Karena tanpa pendidikan yang tinggi setiap individu tidak dapat mewujudkan cita-citanya untuk lebih maju dari kehidupan sebelumnya.

Jalur pendidikan terstruktur dan berjenjang yang terdiri atas pendidikan dasar, pendidikan menengah, dan pendidikan tinggi merupakan jenjang dari pendidikan formal (Machali, 2016). Pendidikan formal sangat penting bagi seorang anak karena pendidikan formal berpusat pada lingkungan sekolah sejak kanak-kanak hingga Perguruan Tinggi. Anak yang putus sekolah memandang bahwa pendidikan formal itu tidak penting bagi masa depannya karena mereka melihat bahwa banyak orang yang bersekolah tetapi akhirnya tetap bekerja tidak sesesuai di inginkan seperti tetap menjadi petani rumput laut (Putri \& Mardhiah, 2020).

Desa Bulu-bulu adalah Desa di Kecamatan Tonra yang berbatasan langsung dengan laut. Sebagian besar penduduk di Desa Bulu-bulu yang menetap di sekitar pesisir bekerja sebagai petani rumput laut. Namun yang menjadi permasalahan pendidikan di daerah tersebut yaitu masih ada beberapa anak petani rumput laut yang telah menyelesaikan pendidikannya sampai ke tingkat SMA tidak melanjutkan lagi pendidikannya ke jenjang Perguruan Tinggi. Hal ini di sebabkan karena mereka lebih memilih bekerja dibandingkan dengan melanjutkan pendidikannya.

Peranan orang tua sangat menentukan tingkat pendidikan formal anaknya. Dalam lembaga keluarga orang tua berperang sebagai pengasuh, pembimbing, dan pendidik bagi anakanaknya (Novrinda et al., 2017). Orang tua sangat terlibat dalam pendidikan formal anaknya, 
karena orang tua dapat memberikan dorongan dan motivasi agar anaknya dapat meningkatkan pendidikannya sampai ke jenjang yang lebih tinggi (Kadriani, 2017). Akan tetapi sikap orang tua yang kurang peduli terhadap pendidikan anaknya dapat menambah jumlah rendahnya mutu pendidikan (N. S. S. Siregar, 2013).

Persepsi orang tua terhadap pendidikan formal sangat mempengaruhi tingkat pendidikan formal anaknya. Orang tua yang memiliki persepsi positif terhadap tingkat pendidikan formal maka tingkat pendidikan formal anaknya juga tinggi, begitupun sebaliknya jika orang tua memiliki persepsi negatif terhadap tingkat pendidikan formal maka tingkat pendidikan formal anaknya juga rendah (S. Siregar, 2018). Berdasarkan hal tersebut tinggi rendahnya tingkat pendidikan anak petani rumput laut di Desa Bulu-bulu tentunya berkaitan dengan bagaimana persepsi petani rumput laut terkait pendidikan.

Persepsi petani rumput terkait pendidikan formal anak berbeda-beda karena persepsi tersebut bersifat pribadi. Beberapa petani rumput laut menganggap bahwa pendidikan itu sangat penting bagi anak begitupun sebaliknya masih ada beberapa petani rumput laut menganggap bahwa pendidikan tidak terlalu penting bagi seorang anak. Selain hal tersebut salah satu faktor yang menghambat pendidikan adalah faktor ekonomi. Tinggi rendahnya tingkat pendidikan juga dipengaruhi oleh kondisi ekonomi orang tua yang berprofesi sebagai petani rumput laut.

Berdasarkan observasi awal pada hari Senin, 28 Desember 2020 ditemukan beberapa permasalahan-permasalah terkait pendidikan formal anak. Permasalahan tersebut yaitu rendahnya minat dan motivasi sebagian petani rumput laut terhadap pendidikan formal anak, penghasilan petani rumput laut tidak cukup untuk membiayai pendidikan anaknya sampai ke jenjang Perguruan Tinggi, adanya anggapan petani rumput laut bahwa anak tidak perlu melanjutkan pendidikannya ke jenjang Perguruan Tinggi karena masih banyak anak yang telah menyelesaikan studinya tetapi masih menjadi pengangguran, dan adanya juga anggapan bahwa anak lebih baik bekerja daripada melanjutkan pendidikannya ke jenjang Perguruan Tinggi.

Berdasarkan permasalahan tersebut maka peneliti tertarik melakukan penelitian yang berjudul "Persepsi Petani Rumput Laut Terhadap Tingkat Pendidikan Formal Anak di Desa Bulu-bulu Kecamatan Tonra Kabupaten Bone".

\section{METODE}

\section{Jenis Penelitian}

Penelitian ini merupakan penelitian deskriptif yang bertujuan untuk mengambarkan atau menjelaskan keadaan umum suatu wilayah.

\section{Waktu dan Tempat Penelitian}

Penelitian di laksanakan di Desa Bulu-Bulu Kecamatan Tonra Kabupaten Bone Sulawesi selatan. waktu pelaksanaan pada penelitian ini yaitu selama satu bulan dari tanggal 15 Maret 2021 sampai 15 April 2021. 
p-ISSN: 1412-8187 e-ISSN: 2655-1284

email: lageografia@unm.ac.id

Jurusan Geografi Fakultas Matematika dan Ilmu Pengetahuan Alam

Universitas Negeri Makassar Sulawesi Selatan, Indonesia

Maddatuang, Suprapta, Wildi Winarti, 2021, Persepsi Petani Rumput Laut Terhadap Tingkat Pendidikan Formal Anak Di Desa Bulu-Bulu Kecamatan Tonra Kabupaten Bone

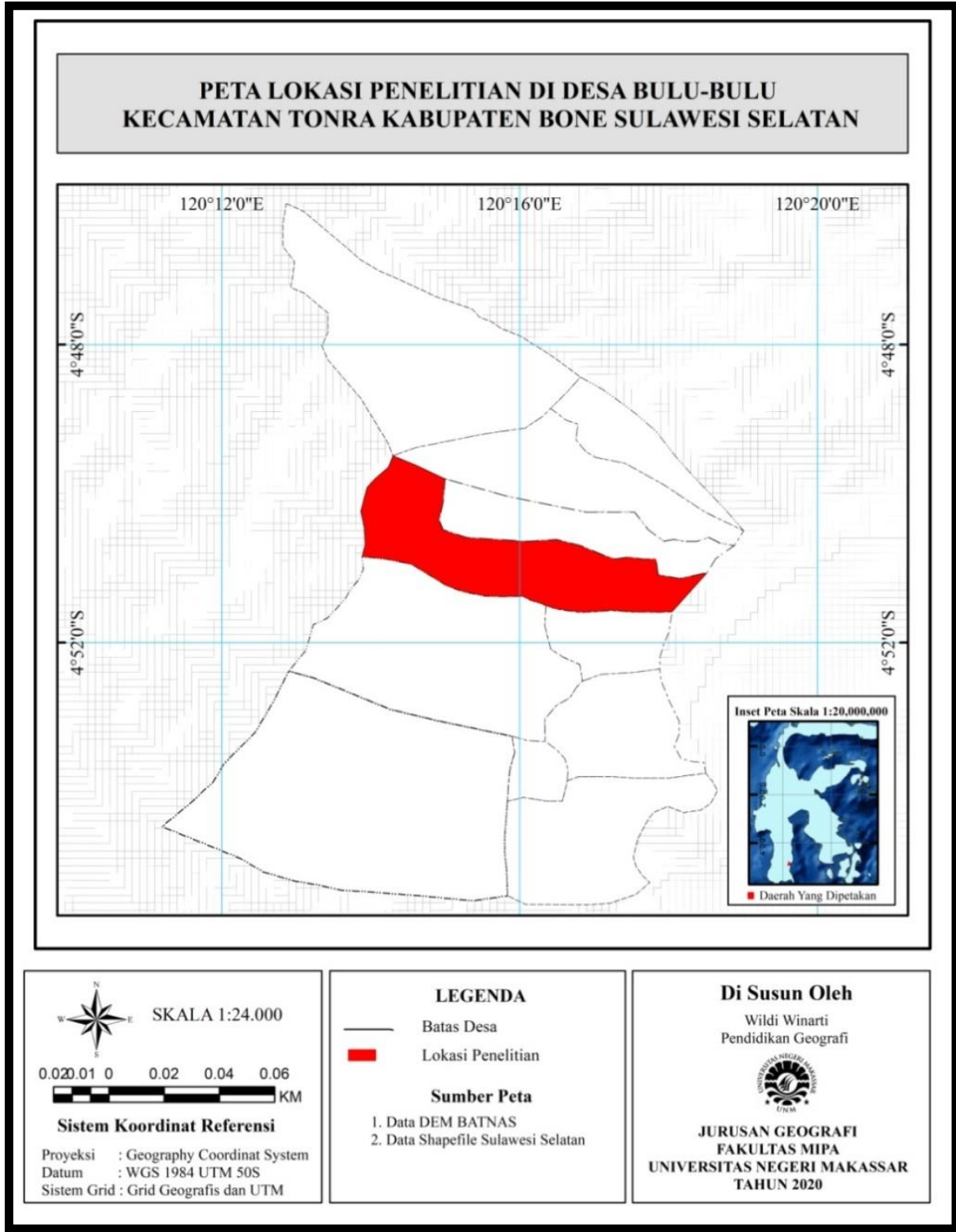

Gambar 1. Peta Lokasi Penelitian

\section{Populasi dan Sampel}

Populasi dalam penelitian ini adalah semua kepala rumah tangga yang mempunyai pekerjaan sebagai petani rumput laut di Desa Bulu-Bulu Kecamatan Tonra yang memiliki modal sendiri dan mengelolahnya sendiri yaitu sebanyak 114 kepala rumah tangga. Adapun teknik pengambilan sampel pada penelitian ini menggunakan teknik Snowball Sampling. Adapun sampel penelitian ini adalah 30 kepala rumah tangga yang bekerja sebagai petani rumput laut 
yang ada di Desa Bulu-Bulu Kecamatan Tonra yang memiliki modal sendiri dan mengelolahnya sendiri.

\section{Teknik Pengumpulan Data}

Teknik pengumppulan data merupakan langkah-langkah yang dilakukan oleh peneliti untuk memperoleh data. Teknik pengumpulan data pada penelitian ini meliputi teknik observasi, wawancara, dan dokumentasi.

\section{Teknik Analisis Data}

Penelitian ini merupakan penelitian yang menggunakan analisis deskriptif untuk menggambarkan dan menjelaskan suatu keadaan atau gejala yang ada di lapangan. Oleh karena itu analisis data dilakukan dengan cara analisis statistik deskriptif. Untuk mengetahui persepsi petani rumput laut terhadap tingkat pendidikan formal anak, diajukan pertanyaan-pertanyaan dalam bentuk kuisioner. Pertanyaan akan diajukan selanjutnya di ukur dengan memakai skala Likert, jawaban-jawaban pertanyaan tersebut diberi skor. Adapun skor 5, 4, 3, 2, dan 1 diberikan untuk pertanyaan positif, sedangkan pertanyaan negatif di beri skor $1,2,3,4$, dan 5 . Pengkaterigorian skor memakai jawaban sangat setuju, setuju, ragu-ragu, tidak setuju, dan sangat tidak setuju.

Tabel 1. Kriteria Skor

\begin{tabular}{cc}
\hline Kriteria & Rentang Skor \\
\hline Sangat Tidak Setuju & $1-15$ \\
Tidak Setuju & $16-30$ \\
Ragu-Ragu & $31-45$ \\
Setuju & $46-60$ \\
Sangat Setuju & $61-75$ \\
\hline
\end{tabular}

Untuk mengetahui bagaimana persepsi petani rumput laut digunakan rumus:

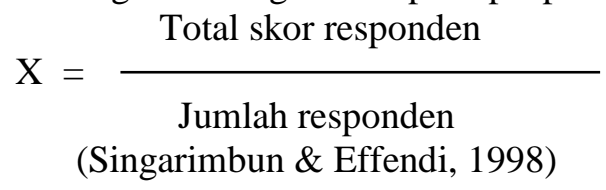

\section{HASIL DAN PEMBAHASAN}

\section{Hasil}

\section{Kondisi Pendidikan Formal Anak Petani Rumput Laut Di Desa Bulu-Bulu} Kecamatan Tonra Kabupaten Bone

Kondisi pendidikan formal anak petani rumput laut dapat dilihat berdasarkan bagaimana tingkat pendidikan formal anaknya baik yang tidak sekolah, sudah putus 
email: lageografia@unm.ac.id

Jurusan Geografi Fakultas Matematika dan Ilmu Pengetahuan Alam

Universitas Negeri Makassar Sulawesi Selatan, Indonesia

Maddatuang, Suprapta, Wildi Winarti, 2021, Persepsi Petani Rumput Laut Terhadap Tingkat Pendidikan Formal Anak Di Desa Bulu-Bulu Kecamatan Tonra Kabupaten Bone

sekolah, yang masih melanjutkan pendidikannya maupun yang sudah menyelesaikan pendidikannya ke jenjang Perguruan Tinggi.

Tabel 2. Kondisi Pendidikan Formal Anak Petani Rumput Laut

\begin{tabular}{lccc}
\hline \multicolumn{1}{c}{ Kondisi Pendidikan } & $\begin{array}{c}\text { Tingkat } \\
\text { Pendidikan }\end{array}$ & Frekuensi & Persentase \\
\hline Belum Sekolah & - & 5 & 6 \\
Tidak pernah sekolah & - & 1 & 1 \\
Masih Melanjutkan Pendidikan & TK & 2 & 2 \\
& SD & 15 & 17 \\
& SMP & 13 & 15 \\
Tidak Melanjutkan Pendidikan & SMA & 13 & 15 \\
& PT & 5 & 6 \\
Tidak Menyelesaikan Pendidikan & SMP & 7 & 9 \\
& SMA & 1 & 1 \\
& PT & 13 & 15 \\
\multicolumn{1}{c}{ Jumlah } & SMP & 1 & 1 \\
SMA & PT & - & 1 \\
Menyelesaikan Pendidikan & PT & 2 & 2 \\
\hline Sumber data: Hasil Analisis Data Tathn & 7 & 9 \\
\hline
\end{tabular}

Sumber data: Hasil Analisis Data Tahun 2021

2. Analisis Persepsi Petani Rumput Laut Terhadap Tingkat Pendidikan Formal Anak Berikut ini persepsi petani rumput laut terhadap tingkat pendidikan formal anak di Desa Bulu-bulu Kecamatan Tonra yang diperolah dari hasil analisis data sebanyak 30 responden yang disajikan dalam bentuk tabel.

Tabel 3. Analisis Persepsi Petani Rumput Laut Terhadap Tingkat Pendidikan Formal Anak

\begin{tabular}{|c|c|c|c|c|c|c|c|c|}
\hline \multirow{2}{*}{ No } & \multirow{2}{*}{ Persepsi } & & \multicolumn{5}{|c|}{ Tanggapan } & \multirow{2}{*}{ Jumlah } \\
\hline & & & $\mathbf{S S}$ & $\mathbf{S}$ & $\mathbf{R R}$ & TS & STS & \\
\hline \multirow{2}{*}{1} & $\begin{array}{l}\text { Persepsi Petani Rumput Laut tentang } \\
\text { Pernyataan Pendidikan Sangat Perlu Bagi }\end{array}$ & $F$ & 7 & 23 & - & - & - & 30 \\
\hline & Anak Petani Rumput Laut & $\%$ & 23 & 77 & - & - & - & 100 \\
\hline \multirow{4}{*}{2} & Persepsi Petani Rumput Laut tentang & & & & & & & \\
\hline & Pernyataan Semakin Tinggi Tingkat & $F$ & 6 & 10 & 3 & 11 & - & 30 \\
\hline & Pendidikan Anak Petani Rumput Laut & & & & & & & \\
\hline & Semakin Baik Pula Masa Depannya & $\%$ & 20 & 33 & 10 & 37 & - & 100 \\
\hline \multirow{2}{*}{3} & $\begin{array}{l}\text { Persepsi Petani Rumput Laut tentang } \\
\text { Pernyataan Anak petani Rumput Laut yang }\end{array}$ & $F$ & 4 & 8 & 7 & 11 & - & 30 \\
\hline & $\begin{array}{l}\text { Tinggi Pendidikannya Dapat Memperbaiki } \\
\text { Usaha Orang Tua dan Kehidupannya }\end{array}$ & $\%$ & 13 & 27 & 23 & 37 & - & 100 \\
\hline
\end{tabular}


email: lageografia@unm.ac.id

Jurusan Geografi Fakultas Matematika dan Ilmu Pengetahuan Alam

Universitas Negeri Makassar Sulawesi Selatan, Indonesia

Maddatuang, Suprapta, Wildi Winarti, 2021, Persepsi Petani Rumput Laut Terhadap Tingkat Pendidikan Formal Anak Di Desa Bulu-Bulu Kecamatan Tonra Kabupaten Bone

\begin{tabular}{|c|c|c|c|c|c|c|c|c|}
\hline \multirow{2}{*}{ No } & \multirow{2}{*}{ Persepsi } & & \multicolumn{5}{|c|}{ Tanggapan } & \multirow{2}{*}{ Jumlah } \\
\hline & & & SS & $\mathbf{S}$ & $\mathbf{R R}$ & TS & STS & \\
\hline \multirow{2}{*}{4} & $\begin{array}{l}\text { Persepsi Petani Rumput Laut Tentang } \\
\text { Pernyataan Setiap Anak Petani Rumput Laut }\end{array}$ & $F$ & 5 & 17 & 3 & 5 & - & 30 \\
\hline & $\begin{array}{l}\text { Seharusnya Mengikuti Pendidikan Formal } \\
\text { dan Tidak Cepat Putus Sekolah }\end{array}$ & $\%$ & 17 & 56 & 10 & 17 & - & 100 \\
\hline \multirow{2}{*}{5} & $\begin{array}{l}\text { Persepsi Petani Rumput Laut Tentang } \\
\text { Pernyataan Tingkat Pendidikan Formal Anak }\end{array}$ & $F$ & 6 & 24 & - & - & - & 30 \\
\hline & $\begin{array}{l}\text { Petani Rumput Laut Seharusnya Lebih } \\
\text { Tinggi Dari Pendidikan Orang Tuanya }\end{array}$ & $\%$ & 20 & 80 & - & - & - & 100 \\
\hline \multirow[b]{2}{*}{6} & $\begin{array}{l}\text { Persepsi Petani Rumput Laut Tentang } \\
\text { Pernyataan Tingkat Pendidikan Formal Anak }\end{array}$ & $F$ & 7 & 22 & - & 1 & - & 30 \\
\hline & $\begin{array}{l}\text { Petani Rumput Laut Baik Laki-Laki Maupun } \\
\text { Perempuan Sebaiknya Sama Karena } \\
\text { Semuanya Membutuhkan Pendidikan }\end{array}$ & $\%$ & 23 & 74 & - & 3 & - & 100 \\
\hline \multirow[b]{2}{*}{7} & $\begin{array}{l}\text { Persepsi Petani Rumput Laut Tentang } \\
\text { Pernyataan Semua Anak Petani Rumput Laut }\end{array}$ & $F$ & 8 & 15 & - & 7 & - & 30 \\
\hline & $\begin{array}{l}\text { Harus Mengikuti Pendidikan Formal Agar } \\
\text { Berilmu Serta Memiliki Bekal dan } \\
\text { Kemampuan }\end{array}$ & $\%$ & 27 & 50 & - & 23 & - & 100 \\
\hline \multirow[t]{2}{*}{8} & $\begin{array}{l}\text { Persepsi Petani Rumput Laut Tentang } \\
\text { Pernyataan Petani Rumput Laut Tidak Perlu } \\
\text { Mengurus Pendidikan Formal Anaknya }\end{array}$ & $F$ & - & 8 & - & 12 & 10 & 30 \\
\hline & Karena Tugasnya Hanya Mencari Uang & $\%$ & - & 27 & - & 40 & 33 & 100 \\
\hline \multirow[b]{2}{*}{9} & $\begin{array}{l}\text { Persepsi Petani Rumput Laut Tentang } \\
\text { Pernyataan Anak Petani Rumput Laut Tidak }\end{array}$ & $F$ & 6 & 8 & - & 7 & 9 & 30 \\
\hline & $\begin{array}{l}\text { Perlu Menuntut Pendidikan yang Tinggi, } \\
\text { Lebih Baik Membantu Orang Tua di Rumah } \\
\text { Mencari Nafkah }\end{array}$ & $\%$ & 20 & 27 & - & 23 & 30 & 100 \\
\hline \multirow{2}{*}{10} & $\begin{array}{l}\text { Persepsi Petani Rumput Laut Tentang } \\
\text { Pernyataan Menuntut Pendidikan Formal } \\
\text { Bagi Anak Petani Rumput Lut Membuano- }\end{array}$ & $F$ & 1 & 13 & - & 10 & 6 & 30 \\
\hline & $\begin{array}{l}\text { Buang Waktu Saja Lebih Baik Digunakan } \\
\text { Untuk Bekerja }\end{array}$ & $\%$ & 3 & 44 & - & 33 & 20 & 100 \\
\hline \multirow[t]{2}{*}{11} & $\begin{array}{l}\text { Persepsi Petani Rumput Laut Tentang } \\
\text { Pernyataan Anak Petani Rumput Laut Yang } \\
\text { Berpendidikan SMA ke Atas Belum Tentu }\end{array}$ & $F$ & 3 & 12 & - & 11 & 4 & 30 \\
\hline & $\begin{array}{l}\text { Bisa Mendapat Pekerjaan Dan Masa Depan } \\
\text { yang Lebih Baik }\end{array}$ & $\%$ & 10 & 40 & - & 37 & 13 & 100 \\
\hline \multirow[t]{2}{*}{12} & $\begin{array}{l}\text { Persepsi Petani Rumput Laut Tentang } \\
\text { Pernyataan Anak Petani Rumput Laut Tidak } \\
\text { Perlu Berpendidikan Sampai Sarjana Karena }\end{array}$ & $F$ & 3 & 12 & - & 9 & 6 & 30 \\
\hline & $\begin{array}{l}\text { Masih Banyak Sarjana yang Masih } \\
\text { Menganggur }\end{array}$ & $\%$ & 10 & 40 & - & 30 & 20 & 100 \\
\hline \multirow[t]{2}{*}{13} & $\begin{array}{l}\text { Persepsi Petani Rumput Laut Tentang } \\
\text { Pernyataan Tingkat Pendidikan Formal Anak } \\
\text { Petani Rumput Laut Seharusnya Sama }\end{array}$ & $F$ & - & - & - & 24 & 6 & 30 \\
\hline & Dengan Tingkat Pendidikan Orang Tua & $\%$ & - & - & - & 80 & 20 & 100 \\
\hline
\end{tabular}


email: lageografia@unm.ac.id

Jurusan Geografi Fakultas Matematika dan Ilmu Pengetahuan Alam

Universitas Negeri Makassar Sulawesi Selatan, Indonesia

Maddatuang, Suprapta, Wildi Winarti, 2021, Persepsi Petani Rumput Laut Terhadap Tingkat Pendidikan Formal Anak Di Desa Bulu-Bulu Kecamatan Tonra Kabupaten Bone

\begin{tabular}{|c|c|c|c|c|c|c|c|c|}
\hline \multirow{2}{*}{ No } & \multirow{2}{*}{ Persepsi } & & \multicolumn{5}{|c|}{ Tanggapan } & \multirow{2}{*}{ Jumlah } \\
\hline & & & SS & $\mathbf{S}$ & $\mathbf{R R}$ & TS & STS & \\
\hline \multirow{4}{*}{14} & Persepsi Petani Rumput Laut Tentang & & & & & & & \\
\hline & Pernyataan Anak Petani Rumput Laut yang & $F$ & 5 & 4 & _ & 15 & 6 & 30 \\
\hline & Perempuan Seharusnya Tidak Usah Sekolah & & & & & & & \\
\hline & $\begin{array}{l}\text { Tinggi-Tinggi (SMA Keatas) Karena Mereka } \\
\text { Akan Cepat Dapat Jodoh }\end{array}$ & $\%$ & 17 & 13 & - & 50 & 20 & 100 \\
\hline \multirow{4}{*}{15} & Persepsi Petani Rumput Laut Tentang & & & & & & & \\
\hline & Pernyataan Jika Orang Tuanya Berprofesi & $F$ & 6 & 6 & - & 12 & 6 & 30 \\
\hline & Sebagai Petani Rumput Laut Maka Lebih & & & & & & & \\
\hline & $\begin{array}{l}\text { Baik Jika Anaknya Mewarisi Profesi Orang } \\
\text { Tuanya Sebagai Petani Rumput Laut }\end{array}$ & $\%$ & 20 & 20 & - & 40 & 20 & 100 \\
\hline \multirow{2}{*}{16} & $\begin{array}{l}\text { Persepsi Petani Rumput Laut Terhadap } \\
\text { Tingkat Pendidikan Formal Anak di Desa }\end{array}$ & $F$ & 12 & 7 & 11 & - & - & 30 \\
\hline & $\begin{array}{l}\text { Bulu-bulu Kecamatan Tonra Kabupaten } \\
\text { Bone }\end{array}$ & $\%$ & 40 & 23 & 37 & - & - & 100 \\
\hline
\end{tabular}

Sumber: Hasil Analisis Data, 2021

Untuk mengetahui skor setiap responden dari keseluruhan pernyataan dapat dilihat pada tabel berikut ini.

Tabel 4. Skor Responden dari Keseluruhan Pertanyaan

\begin{tabular}{cccc}
\hline Responden & Skor & Responden & Skor \\
\hline $\mathbf{1 .}$ & 62 & $\mathbf{1 6 .}$ & 68 \\
$\mathbf{2 .}$ & 63 & $\mathbf{1 7 .}$ & 60 \\
$\mathbf{3 .}$ & 64 & $\mathbf{1 8 .}$ & 38 \\
$\mathbf{4 .}$ & 68 & $\mathbf{1 9 .}$ & 71 \\
$\mathbf{5 .}$ & 73 & $\mathbf{2 0 .}$ & 36 \\
$\mathbf{6 .}$ & 47 & $\mathbf{2 1 .}$ & 43 \\
$\mathbf{7}$ & 60 & $\mathbf{2 2 .}$ & 46 \\
$\mathbf{8 .}$ & 44 & $\mathbf{2 3 .}$ & 66 \\
$\mathbf{9 .}$ & 72 & $\mathbf{2 4 .}$ & 44 \\
$\mathbf{1 0}$ & 50 & $\mathbf{2 5 .}$ & 38 \\
$\mathbf{1 1 .}$ & 66 & $\mathbf{2 6 .}$ & 34 \\
$\mathbf{1 2 .}$ & 33 & $\mathbf{2 7 .}$ & 45 \\
$\mathbf{1 3 .}$ & 49 & $\mathbf{2 8 .}$ & 38 \\
$\mathbf{1 4}$. & 64 & $\mathbf{2 9}$. & 66 \\
$\mathbf{1 5}$. & 38 & $\mathbf{3 0 .}$ & 60 \\
\hline
\end{tabular}

Sumber: Hasil Analisis Data Penelitian Tahun 2021 
Jumlah skor dari 30 responden adalah 1.606 sehingga dari skor tabel di atas didapatkan nilai rata-rata sebagai berikut:

$$
\begin{aligned}
X & =\frac{\text { Skor total seluruh responden }}{\text { Jumlah seluruh responden }} \\
& =\frac{1.606}{30} \\
& =53,5
\end{aligned}
$$

Dari hasil rata-rata 53,5 berarti persepsi petani rumput laut terhadap tingkat pendidikan formal anak adalah berada pada rentang nilai/skor persepsi "setuju".

3. Faktor yang Mempengaruhi Persepsi Petani Rumput Laut Terhadap Tingkat Pendidikan Formal Anak di Desa Bulu-bulu Kecamatan Tonra Kabupaten Bone

Dalam penelitian ini terdapat beberapa faktor yang mempengaruhi persepsi petani rumput terhadap tingkat pendidikan formal anak di Desa Bulu-bulu Kecamatan Tonra Kabupaten Bone. Adapun faktor-faktor tersebut yaitu tingkat pendidikan, tingkat pendapatan, dan curahan kerja. Berikut ini uraian mengenai faktor-faktor tersebut.

\section{a. Tingkat Pendidikan}

\begin{tabular}{|c|c|c|c|c|c|c|c|c|c|c|c|c|}
\hline \multirow{2}{*}{$\begin{array}{l}\text { Persepsi Tingkat } \\
\text { Pendidikan }\end{array}$} & \multicolumn{2}{|c|}{ SS } & \multicolumn{2}{|c|}{$\mathbf{S}$} & \multicolumn{2}{|c|}{$\mathbf{R}$} & \multicolumn{2}{|c|}{ TS } & \multicolumn{2}{|c|}{ STS } & \multicolumn{2}{|c|}{ Jumlah } \\
\hline & $\mathrm{F}$ & $\%$ & $\mathrm{~F}$ & $\%$ & $\mathrm{~F}$ & $\%$ & $\mathrm{~F}$ & $\%$ & $\mathrm{~F}$ & $\%$ & $\mathrm{~F}$ & $\%$ \\
\hline Tidak Tamat SD & - & - & - & - & 1 & 3 & - & - & - & - & 1 & 3 \\
\hline Tamat SD & 5 & 17 & 3 & 10 & 6 & 20 & - & - & - & - & 14 & 47 \\
\hline Tidak Tamat SMP & - & - & - & - & - & - & - & - & - & - & - & - \\
\hline Tamat SMP & 5 & 17 & 3 & 10 & 2 & 7 & - & - & - & - & 10 & 34 \\
\hline Tidak Tamat SMA & - & - & - & - & - & - & - & - & - & - & - & - \\
\hline Tamat SMA & 1 & 3 & 1 & 3 & 2 & 7 & - & - & - & - & 4 & 13 \\
\hline Sarjana & 1 & 3 & - & - & - & - & - & - & - & - & 1 & 3 \\
\hline Jumlah & 12 & 40 & 7 & 23 & 11 & 37 & - & - & - & - & 30 & 100 \\
\hline
\end{tabular}

Tabel 5. Tabulasi Silang Persepsi Petani Rumput Laut Terhadap Tingkat Pendidikan Formal Anak Berdasarkan Tingkat Pendidikan

Sumber: Hasil Analisis Data Penelitian Tahun 2021

\section{b. Tingkat Pendapatan}

\begin{tabular}{|c|c|c|c|c|c|c|c|c|c|c|c|c|}
\hline \multirow{2}{*}{$\begin{array}{l}\text { Persepsi Tingkat } \\
\text { Pendapatan }\end{array}$} & \multicolumn{2}{|c|}{ SS } & \multicolumn{2}{|c|}{$\mathbf{S}$} & \multicolumn{2}{|c|}{$\mathbf{R}$} & \multicolumn{2}{|c|}{ TS } & \multicolumn{2}{|c|}{ STS } & \multicolumn{2}{|c|}{ Jumlah } \\
\hline & $\mathrm{F}$ & $\%$ & $\mathrm{~F}$ & $\%$ & $\mathrm{~F}$ & $\%$ & $\mathrm{~F}$ & $\%$ & $F$ & $\%$ & $\mathrm{~F}$ & $\%$ \\
\hline$<\operatorname{Rp} 500.000$ & - & - & 1 & 3 & - & - & - & - & - & - & 1 & - \\
\hline Rp 510.000-Rp 1.000.000 & 4 & 13 & 1 & 3 & 1 & 3 & - & - & - & - & 6 & 19 \\
\hline Rp 1.010.000-Rp 1.500.000 & 2 & 7 & 2 & 7 & 7 & 24 & - & - & - & - & 11 & 38 \\
\hline$>\mathrm{Rp} 1.500 .000$ & 8 & 27 & 1 & 3 & 3 & 10 & - & - & - & - & 12 & 40 \\
\hline Jumlah & 14 & 47 & 5 & 16 & 11 & 37 & - & - & - & - & 30 & 100 \\
\hline
\end{tabular}

Tabel 6. Tabulasi Silang Persepsi Petani Rumput Laut Terhadap Tingkat Pendidikan Formal Anak Berdasarkan Tingkat Pendapatan 


\section{c. Curahan Kerja}

Tabel 7. Tabulasi Silang Persepsi Petani Rumput Laut Terhadap Tingkat Pendidikan Formal Anak Berdasarkan Curahan Kerja

\begin{tabular}{|c|c|c|c|c|c|c|c|c|c|c|c|c|}
\hline \multirow{2}{*}{ Persepsi Curahan Kerja } & \multicolumn{2}{|c|}{ SS } & \multicolumn{2}{|c|}{$\mathbf{S}$} & \multicolumn{2}{|c|}{$\mathbf{R}$} & \multicolumn{2}{|c|}{ TS } & \multicolumn{2}{|c|}{ STS } & \multicolumn{2}{|c|}{ Jumlah } \\
\hline & $\mathrm{F}$ & $\%$ & $\mathrm{~F}$ & $\%$ & $\mathrm{~F}$ & $\%$ & $\mathrm{~F}$ & $\%$ & $\mathrm{~F}$ & $\%$ & $\mathrm{~F}$ & $\%$ \\
\hline$<4$ jam & - & - & - & - & 1 & 3 & - & - & - & - & 1 & 3 \\
\hline 4-7 jam & 6 & 20 & 2 & 7 & 6 & 20 & - & - & - & - & 14 & 47 \\
\hline$>7$ jam & 6 & 20 & 5 & 17 & 4 & 13 & - & - & - & - & 15 & 50 \\
\hline Jumlah & 12 & 40 & 7 & 24 & 11 & 36 & - & - & - & - & 30 & 100 \\
\hline
\end{tabular}

Sumber data: Hasil Analisis Data Penelitian Tahun 2021

\section{Pembahasan}

\section{Kondisi Pendidikan Formal Anak Petani Rumput Laut di Desa Bulu-bulu Kecamatan} Tonra Kabupaten Bone

Hasil penelitian ini menunjukkan bahwa kondisi pendidikan formal anak petani rumput laut di Desa Bulu-bulu Kecamatan Tonra menyatakan bahwa sebagian besar anak petani rumput laut masih melanjutkan pendidikannya pada tingkat dasar dan tingkat menengah. Sebagaimana yang dikemukakan oleh Miswanto (2018) bahwa menyekolahkan anak merupakan kewajiban bagi orang tua. Pemerintah telah menggalakkan wajib belajar 12 tahun, dimana anak wajib mendapatkan pendidikan formal dari tingkat SD/Sederajat hingga SLTA/Sederajat.

Pendidikan formal sangat penting bagi semua anak termasuk anak petani rumput laut. Keberhasilan pendidikan formal anak dapat ditentukan dari pola asuh yang diterapkan orang tua dari anaknya karena hubungan sekolah dengan orang tua merupakan hubungan yang saling mendukung (Karo-Karo, 2014). Adapun faktor-faktor yang menyebabkan minimnya pendidikan formal anak yaitu motivasi dari anak itu sendiri, kondisi sosial, kondisi ekonomi keluarga, dan motivasi orang tua (Ikhsan et al., 2020). Berdasarkan hal tersebut orang tua sangat berperan penting terhadap tingkat pendidikan formal anaknya.

Anak petani rumput laut yang masih melanjutkan pendidikannya tersebut disertai dengan dukungan dari orang tuanya. Surur, dkk (2020) mengatakan bahwa orang tua berperan penting dalam meningkatkan mutu pendidikan anak sehingga orang tua dapat dijadikan motifasi bagi seorang anak. Berdasarkan hasil wawancara sebagian besar orang tua menginginkan anaknya sukses. Mereka tidak menginginkan anaknya bekerja sebagai petani rumput laut. Sehingga orang tua tersebut mendukung anaknya untuk tetap melanjutkan pendidikaanya dengan alasan agar anaknya bisa mencapai cita-citanya.

Pendapat tersebut sejalan dengan penelitian yang dilakukan oleh (To, 2018) tentang Motivasi Orang Tua dalam Pendidikan Formal Anak (Studi Kasus Masyarakat Nelayan Pulau Keter Laut, Kabupaten Bintan). Yang menyatakan bahwa motivasi orang tua 
terhadap tingkat pendidikan formal anak dapat merubah masa depan anak-anak menjadi lebih baik. Menyekolahkan anak merupakan tujuan orang tua agar anak mereka bisa sukses dan dapat membantu kondisi perekonomian keluarga di kemudian hari. Sehingga hal tersebut dapat membahagiakan keluarga terutama orang tua.

Pada penelitian ini juga terdapat anak petani rumput laut yang telah menyelesaikan pendidikannya tidak semua mendapat pekerjaan karena masih ada yang menganggur. Menurut penelitian (Sukamti, 2018) salah satu faktor yang menyebabkan seseorang tidak bekerja adalah redahnya pendidikan dan keterampilan proses mencari kerja atau dalam hal memilih pekerjaan dan juga gaji yang tidak layak. (S. Sugianto \& Yul, 2020) juga menjelaskan bahwa selain hal tersebut yang dapat menyebabkan banyaknya penganguran yaitu minimnya lapangan pekerjaan sehingga pemerintah harus menciptakan lapangan pekerjaan dan menambah sarana dan prasarana di bidang pendidikan.

Adapun anak petani rumput laut yang tidak melanjutkan pendidikannya karena disebabkan oleh faktor ekonomi keluarga yang tidak mampu, selain faktor tersebut juga diakibatkan oleh faktor non ekonomi seperti rendahnya pendidikan orang tua yang kurang memiliki kemauan dan wawasan untuk masa depan pendidikan anaknya (E. Sugianto \& Bahri, 2017). Selain itu juga terdapat anak petani rumput laut yang tidak pernah sekolah dengan alasan terjadi gangguan jiwa pada anak tersebut sehingga kondisinya tidak memungkinkan untuk sekolah.

Anak petani rumput laut yang tidak melanjutkan pendidikannya sebagian besar dari anak yang pendidikan terakhirnya SMA. Menurut (Lestari et al., n.d.) dalam penelitianna bahwa kurangnya motivasi untuk kuliah dan ingin mandiri mencari pekerjaan merupakan faktor internal yang menyebabkan rendahnya minat melanjutkan pendidikan ke jenjang perguruan tinggi. Anak petani rumput laut tidak melanjutkan pendidikannya ke jenjang Perguruan Tinggi karena mereka lebih memilih bekerja setelah lulus SMA. Adapun pekerjaan anak tersebut ada yang bekerja di kota, ada yang bekerja sebagai penjual, dan bahkan ada yang bekerja sebagai petani rumput laut. Anak yang bekerja sebagai petani rumput laut mewarisi pekerjaan orang tuanya sebagai petani rumput laut.

Anak petani rumput yang tidak menyelesaikan pendidikannya di tingkat Sekolah Dasar disebabkan karena anak tersebut tidak memiliki motivasi untuk sekolah dan orang tuanya pun menuruti keinginan anaknya sehinnga anak tersebut putus sekolah. (Abdullah et al., 2020) menyatakan bahwa orang tua berperan dalam memberikan motivasi kepada anaknya agar anaknya memiliki semangat untuk mengikuti jenjang pendidikan. Selain itu juga anak yang tidak menyelesaikan sekolahnya di tingkat SMA dengan alasan anak tersebut menikah karena kemauan anak itu sendiri dan juga orang tuanya mendukung kemauan anaknya sehingga anaknya juga tidak menyelesaikan pendidikannya. Menurut (Ikhsanudin \& Nurjanah, 2018) pernikahan dini berdampak bagi pendidikan anak yang masih memerlukan bimbingan orang tua sehingga orang tua perlu membimbing anaknya agar anak lebih mengutamakan pendidikannya terlebih dahulu. 
Anak petani rumput laut yang tidak menyelesaikan pendidikannya di tingkat Perguruan Tinggi disebabkan karena faktor ekonomi dan juga ketidak mampuan anak tersebut menempuh pendidikan di Perguruan Tinggi sehingga anak tersebut saat ini bekerja sebagai petani rumput laut. Menurut (Astuti et al., 2021) kondisi ekonomi orang tua yang rendah dapat menghambat tingkat pendidikan anak karena terdapat pengaruh antara pendapatan orang tua dan tingkat pendidikan anak. Namun menurut (Fahmi et al., 2020) kondisi perekonomian orang tua tidak mempengaruhi tingkat pendidikan anak, akan tetapi motivasi diri anak itu sendiri dan kepedulian orang tua dapat mempengaruhi tingkat pendidikan anak.

\section{Persepsi Petani Rumput Laut Terhadap Tingkat Pendidikan Formal Anak di Desa Bulu-bulu Kecamatan Tonra Kabupaten Bone}

Berdasarkan hasil penelitian menunjukkan bahwa pada dasarnya persepsi petani rumput laut terhadap tingkat pendidikan formal anak cukup baik (positif). Petani rumput laut yang memiliki bersepsi positif dilatar belakangi oleh prinsipnya yang ingin menyekolahkan anaknya sampai kejenjang yang lebih tinggi. Karena mereka mempunyai prinsip bahwa tingkat pendidikan formal anaknya harus lebih tinggi dibandingkan tingkat pendidikan responden itu sendiri. Mereka juga berprinsip bahwa semakin tinggi tingkat pendidikan anaknya maka semakin baik juga masa depannya karena mereka tidak ingin anaknya bekerja sebagai petani rumput laut.

Pendapat tersebut juga diperkuat dengan penelitian (Wulandari, 2017) tentang menyatakan bahwa persepsi orang tua terhadap pendidikan formal anak dapat mempengaruhi tingkat pendidikan formal anaknya, semakin baik persepsi orang tua terhadap tingkat pendidikan formal anak maka semakin tinggi pula pendidikan formal anaknya. Miswanto, dkk (2018) juga menjelaskan bahwa persepsi orang tua terhadap tingkat pendidikan formal anak dapat merubah masa depan anak-anak menjadi lebih baik, karena jika seorang anak telah menyelesaikan pendidikannya sampai ke jenjang perguruan tinggi dan mendapatkan pekerjaan secara tidak langsung dapat menaikkan status sosial ekonomi orang tuanya.

Penelitian (Harmayani \& Basri, 2017) menyatakan bahwa pandangan orang tua terhadap pendidikan formal anak sangat penting. Salah satu tujuan pendidikan formal anak yaitu agar anak tersebut mendapatkan ilmu yang banyak yang dapat memperluas wawasannya. Dengan pendidikan formal anak yang tinggi maka anak tersebut berpeluang besar untuk mendapatkan pekerjaan. (Trisnawati et al., 2020) mengatakan bahwa orang tua mempunyai peranan terhadap pendidikan formal anak. Peranan orang tua sebagai pembantu dalam hal membantu menemukan dan menumbuhkan bakat seorang anak. Peranan orang tua mulai dari mengerti dan memahami porsi tugas masing-masing dalam membimbing dan mendidik seorang anak. Sehingga peranan orang tua terhadap pendidikan anak tidak dapat digantikan oleh siapa pun. 
Pada penelitian ini ditemukan juga beberapa petani rumput laut yang memiliki persepsi ragu-ragu terhadap tingkat pendidikan formal anak di sebabkan karena beberapa kendala yang dialami pada saat menyekolahkan anaknya. Salah satu kendalanya adalah biaya pendidikan. Beberapa responden mengeluh terkait biaya pendidikan anaknya karena mahalnya biasa pendidikan sehingga pendapatannya sebagai petani rumput laut masih kurang untuk membiayai pendidikan beberapa anaknya. Jadi mereka harus mencari pekerjaan sampingan agar bisa membayar biaya pendidikan anaknya.

Berdasarkan penelitian (Amsir \& Arifyanto, n.d.) mengatakan bahwa faktor internal yang menghambat pendidikan formal anak ada 2 faktor yaitu faktor internal dan faktor eksternal. Faktor internal meliputi minat, pengetahuan, dan keadaan jasmani sedangkan faktor eksternal meliputi pengaruh lingkungan keluarga, lingkungan pergaulan anak dengan teman sebaya, dan status sosial ekonomi yang minim. Keluarga yang memiliki ekonomi yang tinggi sangat mudah melakukan segala sesuatu terkait pendidikan fornal anaknya. Status ekonomi keluarga yang rendah dapat menjadi penghambat terhadap pendidikan formal anak. Akan tetapi hal tersebut bukanlah salah satu penghalang jika seorang anak dapat memanfaatkan program-program pemerintah seperti bantuan biaya pendidikan bagi keluarga yang kurang mampu.

Bagi petani rumput laut yang tidak mampu membiayai pendidikan anaknya sampai ke jenjang Perguruan Tinggi, Mereka lebih menyarankan anaknya untuk bekerja jika anaknya sudah mampu bekerja, jadi sebagian besar anak petani rumput laut yang sudah tamat SMA lebih disarankan bekerja dibandingkan kuliah. Karena ada beberapa petani rumput laut yang memiliki pendapat bahwa anak yang bisa bekerja lebih baik membantu orang tuanya mencari nafkah. Karena salah satu fakta yang mereka lihat bahwa masih banyak sarjana yang menganggur padahal sudah mengeluarkan biaya yang cukup besar pada saat melanjutkan pendidikannya.

Menurut (Mawar, 2021) dalam penelitiannya yang berjudul Problematika Anak Putus Sekolah di Desa Duwanur Kabuupaten Flores Timur, menyatakan bahwa secara garis besar faktor ekonomi keluarga merupakan penyebab anak tidak melanjutkan pendidikkannya. Oleh karena itu sebagai orang tua sebagai orang tua menghadirkan pekerjaan untuk anak sebagai aktivitas saat tidak melanjutkan sekolahnya. Selain itu kurangnya kemampuan mengikuti pembelajaran juga menjadi faktor penyebab seorang anak tidak melanjutkan pendidikannya. Kurangnya perhatian orang tua terkait hal ini membuat anak tdak melanjutkan pendidikannya karena orang tua merupakan kunci utama dimana anak mendapatkan pendidikan.

3. Faktor yang Mempengaruhi Persepsi Petani Rumput Laut Terhadap Tingkat Pendidikan Formal Anak di Desa Bulu-bulu Kecamatan Tonra Kabupaten Bone

Pada penelitian ini persepsi petani rumput laut terhadap tingkat pendidikan formal anak dipengaruhi oleh 3 faktor yaitu tingkat pendidikan, tingkat pendapatan, dan curahan 
kerja. Tingkat pendidikan petani rumput laut (responden) tentunya dapat mempengaruhi bagaimana persepsinya terhadap tingkat pendidikan formal anaknya. Berdasarkan hasil wawancara yang telah dilakukan masih ada beberapa petani rumput laut (responden) yang memiliki persepsi ragu-ragu terhadap tingkat pendidikan formal anaknya. Persepsi tersebut dipengaruhi oleh tingkat pendidikan responden itu sendiri. Menurut (Muhammad et al., 2017) Semakin tinggi tingkat pendidikan orang tua semakin tinggi pula cita-citanya terhadap tingkat pendidikan formal anaknya. Sehinnga tingkat pendidikan orang tua sangat mempengaruhi tingkat pendidikan formal anaknya.

Tingkat pendapatan juga sangat mempengaruhi persepsi petani rumput laut terhadap tingkat pendidikan formal anak. (Muhammad et al., 2017) juga menjelaskan bahwa pendapatan orang tua yang cukup tinggi dapat memberikan sumbangan positif tehadap tingkat pendidikan formal anak. Semakin tinggi tingkat pendidikan maka semakin banyak pula biaya yang di keluarkan (Nurhadi, 2006). Sehingga untuk melanjutkan pendidikan ke jenjang yang lebih tinggi tentunya membutuhkan biaya yang cukup besar. Berdasarkan hal tersebut tinggi rendahnya pendapatan orang tua sangat berdampak pada tingkat pendidikan anaknya.

Meskipun ada beberapa bantuan pemerintah berupa bantuan biaya pendidikan seperti Kartu Indonesia Pintar, akan tetapi tidak semua anak petani rumput laut mendapatkan bantuan tersebut. Pemerintah sebaiknya memperhatikan kondisi masyarakatnya agar masyarakat yang mendapatkan bantuan tersebut merupakan masyararakat yang sangat membutuhkan. Bantuan biaya pendidikan tersebut sangat penting bagi masyarakat petani rumput laut yang prekonomiannya rendah. Karena dengan adanya bantuan biaya pendidikan kebutuhan pendidikan dapat memenuhi kebutuhan sekolah anak petani rumput laut

Selain tingkat pendidikan dan tingkat pendapatan orang tua, curahan kerja juga merupakan faktor yang dapat mempengaruhi persepsi petani rumput laut terhadap tingkat pendidikan formal anak. Curahan kerja juga berkaitan dengan tingkat pendapatan. Menurut (Jomi et al., 2020) lamanya seseorang bekerja dapat mempengaruhi tingkat pendapatannya. Sehingga curahan kerja juga dapat mempengaruhi persepsi petani rumput laut terhadap tingkat pendidikan formal anak. Sehingga baik atau tidaknya persepsi petani rumput laut terhadap tingkat pendidikan formal anak juga tergantung dari curahan kerjanya.

Berdasarkan penelitian (Irwan, n.d.) tentang Persepsi Keluarga Petani Terhadap Pendidikan Formal Anak di Desa Sungai Toman Kecamatan Salatiga Kabupaten Sambas. Penelitian ini mendukung penelitian saya yang mengatakan bahwa persepsi keluarga petani terhadap pendidikan formal anak dipengaruhi oleh faktor Latar belakang pendidikan orang tua dan kondisi perekonomian orang tua (tingkat pendapatan. Sehingga faktor tersebut dapat menjadi latar belakang penyebab anak putus sekolah.

(Adri, 2019) menyatakan bahwa faktor yang mendukung persepsi orang tua terhadap pendidikan formal anak terdiri dari dua faktor yaitu ada faktor penghambat dan 
ada juga faktor pendukung. Faktor penghambat terdisi atas kurangnya minat anak untuk sekolah dan terbatasnya ekonomi orang tua. Sedangkan faktor pendukung meliputi adanya informasi tentang pendidikan diberbagai media, motivasi dan dorongan keluarga yang tinggi terkait pendidikan, adanya minat pribadi anak dalam belajar guna untuk melanjutkan pendidikannya, dan adanya kedekatan yang baik antara orang tua dengan anak sehingga hubungan orangtua dengan anak baik.

\section{SIMPULAN DAN SARAN}

\section{Simpulan}

Berdasarkan hasil penelitian di lapangan dan hasil analisis data dari 30 responden maka dapat di tarik kesimpulan bahwa kondisi pendidikan formal anak petani rumput laut di Desa Bulu-bulu Kecamatan Tonra dinyatakan bahwa sebagian besar anak petani rumput laut masih melanjutkan pendidikannya pada tingkat dasar dan tingkat menengah. Persepsi petani rumput laut terhadap tingkat pendidikan formal anak di Desa Bulu-bulu Kecamatan Tonra tergolong cukup baik (Positif). Persepsi petani rumput laut terhadap tingkat pendidikan formal anak dipengaruhi oleh beberapa faktor yaitu tingkat pendidikan, tingkat pendapatan, dan curahan kerja. Ketiga faktor tersebut saling berkaitan antara satu sama lain.

\section{Saran}

Berdasarkan kesimpulan di atas, berikut ini terdapat beberapa saran yang dapat diberikan bagi pemerintah setempat sebaiknya memberikan dorongan kepada petani rumput laut agar tetap mendukung anaknya dalam melanjutkan tingkat pendidikan formal sampai ke jenjang Perguruan Tinggi. Bagi petani rumput laut (orang tua) diharapkan agar lebih mementingkan tingkat pendidikan anaknya. Anak seharusnya lebih baik melanjutkan pendidikannya ke jenjang Perguruan Tinggi dari pada bekerja, karena pendidikan merupakan investasi masa depan. Bagi anak petani rumput laut yang lulus SMA seharusnya tidak langsung bekerja akan tetapi lebih baik jika melanjutkan pendidikannya ke jenjang perguruan tinggi.

\section{DAFTAR RUJUKAN}

Abdullah, M. R., Pairin, P., \& Rasmi, R. (2020). Analisis Faktor Penyebab Anak Putus Sekolah di Kecamatan Amonggedo Kabupaten Konawe. DIRASAH: JURNAL PENDIDIKAN ISLAM, 1(1), 19-25.

Adri, J. (2019). Persepsi orang tua terhadap pentingnya pendidikan anak di desa taduasa kecamatan batuatas kabupaten buton selatan. Jurnal Akademik Pendidikan Ekonomi, 6(1).

Amsir, J., \& Arifyanto, A. T. (n.d.). FAKTOR-FAKTOR PENGHAMBAT PERENCANAAN KARIR SISWA. Jurnal Ilmiah Bening: Belajar Bimbingan Dan Konseling, 5(1), 57-66.

Astuti, W., Sion, H., \& Erang, D. (2021). Pengaruh Pendidikan dan Pendapatan Orang Tua Terhadap Tingkat Pendidikan Anak Keluarga Nelayan Tradisional Kecamatan Seruyan Hilir Kabupaten Seruyan. Edunomics Journal, 2(1), 35-42.

Burdames, Y., \& Ngangi, E. L. A. N. L. A. (2014). Kondisi Lingkungan Perairan Budi Daya 
Rumput Laut di Desa Arakan, Kabupaten Minahasa Selatan. E-Journal BUDIDAYA PERAIRAN, 2(3).

Fahmi, F., Bakhtiar, Y., Saleh, A., Ismail, A. F.-H., Tandewi, S. A. M. S., Lubis, F. A. S., Silitonga, D. N. F., Syahidah, D. M., Umam, F. K., \& Noor, M. I. F. (2020). Pengaruh Status Sosial Ekonomi Orang Tua Terhadap Tingkat Pendidikan Anak. Jurnal Pusat Inovasi Masyarakat (PIM), 2(6), 996-1002.

Harmayani, H., \& Basri, B. (2017). Persepsi Keluarga Petani Terhadap Pendidikan Formal Anak (Studi Tentang Keluarga Anak Putus Sekolah Di Desa Baturijal Hulu Kecamatan Peranap Kabupaten Indragiri Hulu). Riau University.

Ikhsan, A. M., Hasriyanti, H., \& Syarif, E. (2020). Pendidikan Formal Anak Dalam Perspektif Nelayan Suku Bajo di Kampung Bajo. LaGeografia, 18(3), 269-288.

Ikhsanudin, M., \& Nurjanah, S. (2018). Dampak Pernikahan Dini Terhadap Pendidikan Anak Dalam keluarga. Al-I'tibar: Jurnal Pendidikan Islam, 5(1), 38-44.

Irwan, I. (n.d.). Persepsi Keluarga Petani terhadap Pendidikan Formal Anak di Desa Sungai Toman Kecamatan Salatiga Kabupaten Sambas. Tanjungpura University.

Jomi, M., Widodo, S., \& Hariani, E. (2020). Analisis Faktor-Faktor yang Mempengaruhi Pendapatan Pedagang di Pasar Reok Kabupaten Manggarai Nusa Tenggara Timur Tahun 2020. Economie, 2(1), 1-16.

Karo-Karo, D. (2014). Membangun Karakter Anak dengan Mensinergikan Pendidikan Informal dengan Pendidikan Formal. Elementary School Journal Pgsd Fip Unimed, 1(2).

Kurniawan, R. Y. (2016). Identifikasi permasalahan pendidikan di Indonesia untuk meningkatkan mutu dan profesionalisme guru. Konvensi Nasional Pendidikan Indonesia, $1415-1420$.

Lestari, M., Zakso, A., \& Al Hidayah, R. (n.d.). FAKTOR-FAKTOR PENYEBAB RENDAHNYA MINAT MELANJUTKAN PENDIDIKAN KE PERGURUAN TINGGI (KASUS PADA REMAJA DI DESA SEPADU). Jurnal Pendidikan Dan Pembelajaran Khatulistiwa, 9(7).

Mawar, R. (2021). PROBLEMATIC OF CHILDREN DROPPED OUT OF SCHOOL IN DUWANUR VILLAGE, EAST FLORES. Sociological Education, 2(1), 29-35.

Muhammad, M., Gani, H., \& Arifin, A. (2017). Pengaruh Faktor Sosial Ekonomi Orang Tua Terhadap Minat Melanjutkan Pendidikan Anak di Desa Wunse Jaya Kecamatan Wawonii Tenggara Kabupaten Konawe Kepulauan. Al-TA'DIB: Jurnal Kajian Ilmu Kependidikan, 10(1), 163-180.

Novrinda, N., Kurniah, N., \& Yulidesni, Y. (2017). Peran Orangtua Dalam Pendidikan Anak Usia Dini Ditinjau Dari Latar Belakang Pendidikan. Jurnal Ilmiah Potensia, 2(1), 39-46.

Nurhadi, M. A. (2006). Desentralisasi dan Mahalnya Biaya Pendidikan. Jurnal Manajemen Pendidikan, 2(2).

Putri, E., \& Mardhiah, D. (2020). Pemaknaan Anak Petani Terhadap Pendidikan Formal di Jorong Kaludan Nagari Sungai TalangKecamatan Guguak Kabupaten Lima Puluh Kota. Jurnal Perspektif: Jurnal Kajian Sosiologi Dan Pendidikan, 3(3).

Singarimbun, M., \& Effendi, S. (1998). Metode Penelitian Sosial. Jakarta: LP3ES.

Siregar, N. S. S. (2013). Persepsi orang tua terhadap pentingnya pendidikan bagi anak. JPPUMA: Jurnal Ilmu Pemerintahan Dan Sosial Politik UMA (Journal of Governance and Political Social UMA), 1(1), 11-27.

Siregar, S. (2018). Persepsi Orangtua Tentang Pendidikan Tinggi Bagi Anak Perempuan Di 
Desa Simatorkis Kec. Dolok Kab. Padanglawas Utara. Jurnal Kajian Gender Dan Anak, 2(2), 171-190.

Sugianto, E., \& Bahri, S. (2017). Faktor Penyebab Anak Putus Sekolah Tingkat SMA di Desa Bukit Lipai Kecamatan Batang Cenaku Kabupaten Inderagiri Hulu. Riau University.

Sugianto, S., \& Yul, Y. T. P. (2020). FAKTOR PENYEBAB PENGANGGURAN DAN

STRATEGI PENANGANANPERMASALAHAN PENGANGGURAN PADA DESA BOJONGCAE, CIBADAK LEBAK PROVINSI BANTEN. IKRA-ITH EKONOMIKA, $3(2), 54-63$.

Sukamti, D. (2018). Penyebab Tingginya Angka Pengangguran di Kota Metro. IAIN Metro.

To, M. W. (2018). MOTIVASI ORANG TUA DALAM PENDIDIKAN FORMAL ANAK: STUDI KASUS MASYARAKAT NELAYAN PULAU KETER LAUT, KABUPATEN, BINTAN. Asian People Journal (APJ), 1(2), 222-242.

Trisnawati, W., Oktavia, D., \& Putra, I. M. (2020). SOSIALISASI PERANAN ORANG TUA TERHADAP PENDIDIKAN ANAK DI DESA TIRTA KENCANA. Jurnal Pengabdian Pendidikan Masyarakat (JPPM), 1(1), 28-34.

Tubu, B., Malik, A., \& Syarif, E. (2021). Persepsi Masyarakat Terhadap Pendidikan Formal Kaitannya dengan Jumlah Anak-anak Putus Sekolah. LaGeografia, 19(3).

Ustama, D. D. (2009). Peranan pendidikan dalam pengentasan kemiskinan. Dialogue, 6(1), 112.

Wulandari, A. (2017). Pengaruh Persepsi Orang Tua Tentang Pendidikan Formal Dan Lingkungan Tempat Tinggal Terhadap Pekerja Anak Di Kelurahan Pidada Kecamatan Panjang Kota Bandar Lampung.

Yusuf, A. (2014). Analisis kebutuhan pendidikan masyarakat. Jurnal Penelitian Pendidikan, $31(2)$. 